\title{
SPECT, MRI and cognitive functions in multiple sclerosis
}

Carlo Pozzilli, Domenico Passafiume, Silvia Bernardi, Patrizia Pantano, Chiara Incoccia, Stefano Bastianello, Luigi Bozzao, Gian Luigi Lenzi, Cesare Fieschi

\begin{abstract}
Seventeen patients with relapsing remitting multiple sclerosis (MS) and mild physical disability had neuropsychological testing, magnetic resonance imaging (MRI) and single photon emission computerised tomography (SPECT) using technetium 99m (99mTc) hexamethyl-propyleneamine oxime (HMPAO). Performance in verbal fluency, naming and memory testing appeared to be impaired in MS patients compared with 17 age-sex and education matched normal controls.

Weighted periventricular and confluent lesion scores and the width of the third ventricle, proved to be the most sensitive MRI measures in differentiating more cognitively impaired patients from those who were relatively unimpaired.

Ratios of regional to whole brain activity, measured by SPECT, showed significant reduction in the frontal lobes and in the left temporal lobe of MS patients. A relationship was found between left temporal abnormality in $99 \mathrm{mTc}-H M P A O$ uptake and deficit in verbal fluency and verbal memory. Finally, asymmetrical lobar activity indicated a predominant left rather than right temporo-parietal involvement.
\end{abstract}

Department of Neurological Science C Pozzilli

S Bernardi

P Pantano

$S$ Bastianello

L Bozzao

G Lenzi

C Fieschi

Department of

Psychology

C Incoccia

University of

L'Aquila, Rome, Italy

Department of

Environmental

Science

D Passafiume

Presented as an abstract at the 14th International

Symposium on Cerebral

Blood Flow and Metabolism,

"Brain 89", Bologna, 28th

May-1st June 1989

Correspondence to:

Dr Pozzilli, Department of

Neurological Science,

University of Rome, Viale

dell'Università 30, 00185

Rome, Italy.

Received 11 December 1989 and in revised form

18 April 1990.

Accepted 15 May 1990

A substantial proportion of patients with multiple sclerosis (MS) show disturbance of higher cognitive functions. ${ }^{1-5}$ Cognitive decline is more frequent at the more advanced stage of the disease ${ }^{6}$ and in chronic progressive MS. ${ }^{7}$ It may, however, also be present in the early phase ${ }^{89}$ and in patients with mild physical disability. ${ }^{1011}$ The extent of cognitive impairment is related to cerebral ventricular size $^{12}$ corpus callosum atrophy ${ }^{1314}$ and degree of cerebral lesions quantified by magnetic resonance imaging (MRI). ${ }^{14-18}$

Previous work using positron emission tomography (PET) has demonstrated a generalised coupled reduction in both cerebral oxygen utilisation and blood flow in MS patients. The reduction was found in both white and grey matter and correlated with cognitive impairment, rather than with locomotor disability or clinical disease duration. ${ }^{19}$ Recently, single photon emission computed tomography (SPECT) has given information similar to that provided by PET in the study of cognitive deficit associated with Alzheimer's dementia. ${ }^{20-22}$

The aim of this study was to examine the regional distribution of $99 \mathrm{mTc}$ HMPAO in the brain, the extent of cerebral lesions by MRI and their relationship to neuropsychological findings in MS. Our study specifically addresses the relapsing-remitting MS type with relatively mild physical and cognitive disturbance.

\section{Materials and methods \\ Patients}

Seventeen right handed MS patients (12 women and five men), mean (SD) age 31 (10) years and educational level $14(3.5)$ years were selected from those admitted to our MS outpatient clinic. The patients were evaluated according to the Schumacher criteria as having clinically definite MS. ${ }^{23}$ The diagnosis was further supported by evoked potentials and CSF studies. All patients had a relapsingremitting form of $\mathrm{MS}^{24}$ and they were studied during a stationary phase. At least three months elapsed between the occurrence of an exacerbation or the termination of therapy (steroids/corticotropin) and testing.

Excluded from the study were any patients who did not meet the criteria of definite MS or whose disease course was chronic-progressive. Patients with EDSS score $>4$ or those with Mini Mental State Examination (MMSE) lower than 23 were also excluded.

Mean (SD) clinical disease duration was as estimated by the Kurtzke Expanded Disability Status Scale (EDSS) ${ }^{25}$ was $1.7(1.0)$ and mean MMSE was $28 \cdot 5(1 \cdot 7)$.

\section{Neuropsychological assessment}

The neuropsychological test battery ${ }^{26}$ consisted of measures of general intelligence, language, memory, attention and visuospatial abilities lasting approximately two hours. The battery was composed of the following tests:

General intelligence Coloured Progressive Matrices. This test was administered following the standard procedure to provide an estimate of non verbal general intelligence.

Abstract/conceptual reasoning Wisconsin Sorting Card Test. This was administered following the standard procedure. The number of perseverative errors were recorded as a measure of abstracting ability.

Language Boston Naming Test. ${ }^{27}$ In this test of confrontational naming ability, subjects 
were shown line drawings, one at a time, of 60 objects that varied in familiarity. The total number of correct responses serves as the score.

Set test. This is a verbal fluency test, based on the number of components in a given category that the subject can denominate in 120 s. We adopted the categories "furniture" and "birds". Scoring is the mean of names produced in the two categories.

Visuospatial abilities Street Completion Test. This is a test of "speed of closure". We adopted the 11 items version. Each item is composed by an incomplete black figure of a common object that has to be identified. Scoring is on pass/fail basis.

Elithorn's Perceptual Maze Test. This is composed of an 18 lattice type maze and the subject has to trace a line from bottom to top of the maze, through the maximum number of black points randomly placed on the net figure. The scoring is on time and number of black point basis.

Verbal memory Digit Span. We administered and scored this subtest of WAIS following standard instructions.

Rey Auditory Verbal Learning. A list of 15 stimulus-name of common objects is read five times by the examiner to the subject. After each presentation the subject has to repeat as many words as he/she can recall. We assigned two different scores. Short term memory scores: number of words recalled after the first presentation; Long term memory scores: the words correctly reported after a $15 \mathrm{~min}$ utes delay.

Visuospatial memory Corsi Tapping Test. The subject is presented with nine blocks impartially arranged on a board. The examiner taps the blocks, and the subject is required to tap the same blocks in exactly the same pattern. Scoring is the longest sequence of blocks correctly tapped.

Rey Osterreith Complex Figure. The subject is presented with a complex geometrical drawing that he/she has to reproduce first by copying and after 15 minutes from memory. Scores are the number of element correctly reproduced and placed.

Seventeen normal controls (NC) matched one to one with the patients in terms of age, sex and education level, were recruited from the community. Normal controls were people from the hospital staff without a history of central nervous system disease or alcohol abuse. Normal controls were evaluated using the same neuropsychological procedures as those used for patients.

\section{$M R I$}

MRI studies were performed with a 1.5 Tesla superconductive unit (Philips, Gyroscan S15). T1 weighted spin-echo sequences (TR 350, TE 30) on sagittal plane and both axial and coronal T2 weighted spin-echo sequences (TR 2300, TE 30-120) were obtained from each patient. Hyperintense demyelinating areas, easily seen on proton density and $\mathrm{T} 2$ weighted images, were quantified by a neuro- radiologist (LB) blind to the clinical and neuropsychological findings.

Lesions were divided into two categories: single lesions and confluent lesions. Single lesions were defined as rounded areas of abnormal high signal intensity. Confluent lesions have an appearance of more than one rounded single lesion having come together to form an irregularly shaped "lump" or thick $\left(>5 \mathrm{~mm}\right.$ ) linear area abnormality. ${ }^{28}$

Weighted lesion scores were developed based on the number and size of lesions. We assigned the following weights according to lesion size: $1=<8 \mathrm{~mm} ; 2=8-20 \mathrm{~mm}$; $3=>20 \mathrm{~mm}$.

Lesions which were periventricular in part and extended out into the brain parenchyma were considered "periventricular", while lesions which were apparently separate from the ventricles were designated "discrete" cerebral lesions. ${ }^{29}$ This latter group included both "pure" white matter lesions and those located just beneath the cortical surface (greywhite matter junctions).

The evaluation of the corpus callosum (CC) was carried out on sagittal T1 weighted images. To obtain area measurements of CC and cerebral hemisphere, the outlines of these structures were traced on a monitor screen with a cursor and their areas were then calculated by a means of a computerised graphic table. The $\mathrm{CC} /$ brain area ratio was calculated and then analysed. ${ }^{30}$

Finally, linear measurements were recorded including: (1) Frontal Horn Index, the ratio of the maximal distance between the lateral border of the frontal horns and the maximal width of the outer skull table at the same level; (2) Cella Media Index, the ratio of the minimal width of the lateral ventricles at the cella media level to outer skull table at the same level; (3) Third Ventricular Index, the ratio of the maximal width of the third ventricle and width of outer skull at the same level.

\section{SPECT}

SPECT brain imaging was performed with a rotating gamma camera (GE $400 \mathrm{~T}$ ) connected to a dedicated computer (HP 1000, Eurobit).

Twenty $\mathrm{mCi}$ of $99 \mathrm{~m}$ Tc HMPAO was injected into an antecubital vein with the patient sitting quietly in a softly lit room. After 10 minutes, patients were placed supine using a head holder to minimise motion. Acquisitions were made recording 64 angular views using a $64 \times 64$ matrix format. In 30 minutes four million total counts were collected. After reconstruction, a complete set of axial tomographic slices from the posterior fossa up to the vertex was obtained. The slice thickness was $1.2 \mathrm{~cm}$ and the spatial resolution was $2 \cdot 1 \mathrm{~cm}$ full width half maximum (FWHM). SPECT scans were evaluated by an investigator (PP) blind to the clinical and neuropsychological data.

The following axial tomographic slices were considered; one slice corresponding to the plane defined by the cerebellum (OM + $2 \cdot 1 \mathrm{~cm}$ ) and three supratentorial cerebral slices corresponding to the level of the basal 
Table 1 Mean (SD) row scores and significance for group comparison on the neuropsychological battery

\begin{tabular}{|c|c|c|c|}
\hline Tests & Normal controls $(n=17)$ & $M S$ patients $(n=17)$ & $p^{\star}$ \\
\hline $\begin{array}{l}\text { General intelligence: } \\
\text { Progressive matrices }\end{array}$ & $33 \cdot 2(2 \cdot 8)$ & $31 \cdot 6(3 \cdot 2)$ & NS \\
\hline $\begin{array}{l}\text { Abstract/conceptual reasoning: } \\
\text { Wisconsin card sorting }\end{array}$ & $6.9(10 \cdot 4)$ & $11.5(14.7)$ & NS \\
\hline $\begin{array}{l}\text { Language: } \\
\text { Boston naming } \\
\text { Set }\end{array}$ & $\begin{array}{l}52 \cdot 7(5 \cdot 4) \\
29 \cdot 4(7 \cdot 1)\end{array}$ & $\begin{array}{l}46 \cdot 8(6 \cdot 8) \\
24 \cdot 4(6 \cdot 2)\end{array}$ & $\begin{array}{l}0.014 \\
0.024\end{array}$ \\
\hline $\begin{array}{l}\text { Visuospatial abilities: } \\
\text { Street completion } \\
\text { Elithorn's perceptual maze }\end{array}$ & $\begin{array}{r}9 \cdot 0(2 \cdot 1) \\
28 \cdot 4(3 \cdot 4)\end{array}$ & $\begin{array}{r}8 \cdot 2(2 \cdot 1) \\
27 \cdot 4(3 \cdot 4)\end{array}$ & $\begin{array}{l}\text { NS } \\
\text { NS }\end{array}$ \\
\hline $\begin{array}{l}\text { Verbal memory: } \\
\text { Digit span } \\
\text { Rey auditory verbal learning: } \\
\text { Short term } \\
\text { Long term }\end{array}$ & $\begin{array}{l}10 \cdot 5(2 \cdot 6) \\
7 \cdot 2(1 \cdot 3) \\
13 \cdot 1(1 \cdot 5)\end{array}$ & $\begin{array}{rr}10 \cdot 4 & (2 \cdot 4) \\
& \\
6 \cdot 1 & (1 \cdot 5) \\
11 \cdot 1 & (2 \cdot 2)\end{array}$ & $\begin{array}{l}\text { NS } \\
0.015 \\
0.009\end{array}$ \\
\hline $\begin{array}{l}\text { Visuospatial memory: } \\
\text { Corsi tapping } \\
\text { Rey-Osterreith Complex } \\
\text { figure memory }\end{array}$ & $\begin{array}{r}5.6(0.9) \\
21.6(7 \cdot 5)\end{array}$ & $\begin{array}{r}5 \cdot 5(1 \cdot 3) \\
16 \cdot 4(8 \cdot 1)\end{array}$ & $\begin{array}{l}\text { NS } \\
0.040\end{array}$ \\
\hline
\end{tabular}

$\star$ Derived from paired Student's $t$ test (two tailed).

ganglia, the corona radiata and centrum semiovale $(\mathrm{OM}+4.5 \mathrm{~cm}, 5.7 \mathrm{~cm}, 6.9 \mathrm{~cm})$ respectively.

Scans were analysed semiquantitatively by measuring tracer uptake in 16 regions of interest (ROIs), $4 \times 4$ pixels, $(24 \times 24 \mathrm{~mm})$. The ROIs were placed in the right and left supero-frontal, infero-frontal, antero-superotemporal, postero-infero-temporal, superoparietal, infero-parietal, occipital lobes and cerebellum.

Normalised regional activity rates $(Q$ values) were expressed as a ratio of activity per pixel in the ROIs to the activity per pixel in the whole brain. Normalised lobar activity rates were also calculated, reflecting the mean value for the ROIs contained in the frontal, parietal, temporal and occipital lobes.

Asymmetry indices for each lobe were expressed as left to right count ratio according to the formula $(R-L) /(R+L) \times 200$.

The ratios for MS patients were compared with those obtained fron nine age-matched healthy controls with no known neurological disorders.

Table 2 Clinical and MRI characteristic of MS patients with and without cognitive impairment

\begin{tabular}{|c|c|c|c|}
\hline Mean (SD) & $\begin{array}{l}\text { "Cognitively" intact } \\
(n=9)\end{array}$ & $\begin{array}{l}\text { "Cognitively" impaired } \\
(n=8)\end{array}$ & $p^{\star}$ \\
\hline $\begin{array}{l}\text { Age, years } \\
\text { Education, years } \\
\text { Disease duration, years } \\
\text { EDSS } \\
\text { Mini Mental State }\end{array}$ & $\begin{aligned} & 30 \cdot 4(8 \cdot 7) \\
& 14 \cdot 7(2 \cdot 1) \\
& 7 \cdot 1(4 \cdot 2) \\
& 1 \cdot 6(1 \cdot 2) \\
& 29 \cdot 4(0 \cdot 5)\end{aligned}$ & $\begin{aligned} 32.9 & (10.9) \\
12.1 & (4 \cdot 1) \\
6.4 & (6 \cdot 8) \\
1.8 & (1 \cdot 0) \\
27.5 & (2 \cdot 0)\end{aligned}$ & $\begin{array}{l}\text { NS } \\
\text { NS } \\
\text { NS } \\
\text { NS } \\
0.012\end{array}$ \\
\hline $\begin{array}{l}\text { MRI measures: } \\
\text { Total lesion score } \\
\text { L/R total lesion score } \\
\text { Total periventricular score } \\
\text { L/R periventricular score } \\
\text { Discrete lesion score } \\
\text { Confluent lesion score } \\
\text { Callosal-brain ratio } \\
\text { Frontal horn index } \\
\text { Third ventricle index } \\
\text { Cella media index }\end{array}$ & $\begin{aligned} 35.4 & (16 \cdot 3) \\
1.0 & (0 \cdot 2) \\
11.6 & (5 \cdot 4) \\
1.1 & (0 \cdot 3) \\
23.9 & (14.4) \\
1.7 & (2 \cdot 6) \\
7.0 & (1 \cdot 5) \\
31.8 & (2 \cdot 6) \\
4.4 & (0 \cdot 8) \\
21.7 & (3 \cdot 0)\end{aligned}$ & $\begin{aligned} 40.0 & (13.8) \\
1.2 & (0.4) \\
20.9 & (7 \cdot 6) \\
0.9 & (0.2) \\
18.8 & (10 \cdot 8) \\
7.1 & (4.5) \\
7.8 & (1 \cdot 2) \\
31.1 & (3.0) \\
5.3 & (1 \cdot 0) \\
22.7 & (3.9)\end{aligned}$ & $\begin{array}{l}\text { NS } \\
\text { NS } \\
0 \cdot 010 \\
\text { NS } \\
\text { NS } \\
0 \cdot 008 \\
\text { NS } \\
\text { NS } \\
0 \cdot 049 \\
\text { NS }\end{array}$ \\
\hline
\end{tabular}

Derived from unpaired Student's $t$ test (two tailed)

${ }^{\star}$ Left/right ratio.

\section{Results}

Neuropsychological testing

Table 1 compares neuropsychological performance of MS patients with that of controls. The data were analysed by Student's $t$ tests to detect specific group differences in each of the neuropsychological measures. Five tests showed significant group differences: patients with MS were significantly impaired in terms of verbal fluency, naming and memory deficits.

The patient sample was then divided into two groups: (1) patients who were relatively "cognitively impaired" with 2 SD below normal control performance on at least two or more neuropsychological tests; (2) patients who were relatively "cognitively intact" with an impairment on one or less of the neuropsychological measures.

Out of the eight patients classified as "cognitively impaired", three patients failed on 2 neuropsychological measures, two patients on 3 measures and the remaining three patients on 4, 6 and 8 measures respectively.

Table 2 describes demographic, clinical and MRI characteristics of the two MS groups. As shown in table 2, patients with cognitive impairment were significantly more likely to show abnormalities in the Mini Mental State test,

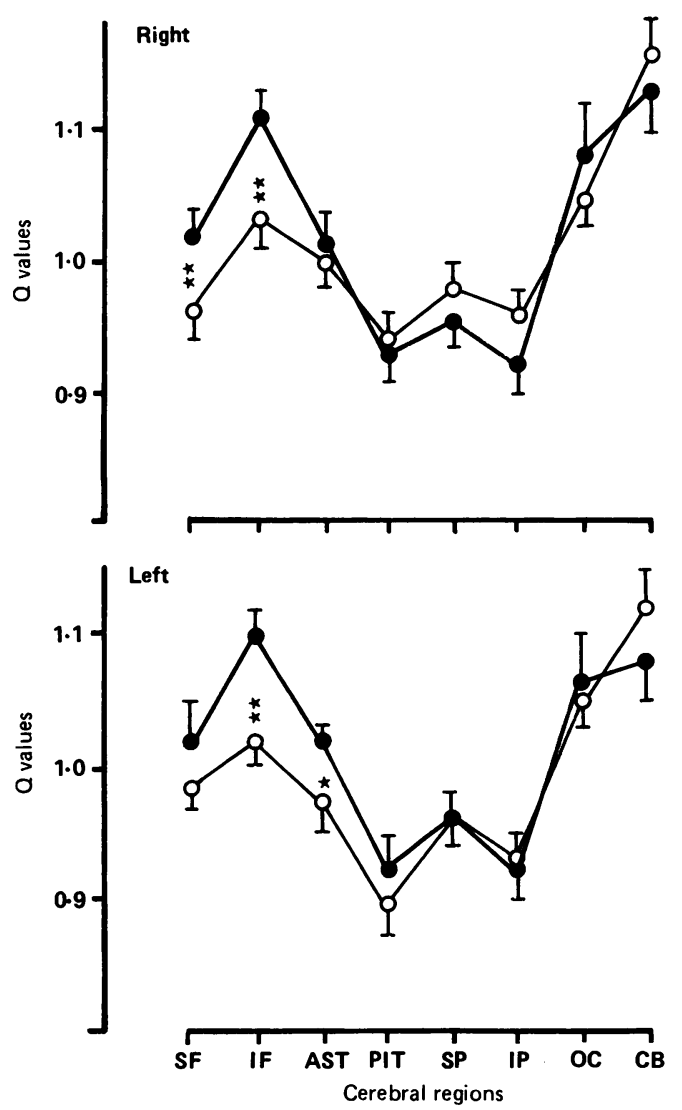

Figure 1 Mean ( $S E$ ) regional $Q$ values (single $R O I$ count/whole brain counts) for right (top) and left (bottom) (white circle) and nine normal controls (black circle).

$S F$ indicates Supero-frontal; IF, Infero-frontal; $A S T$, Antero-supero-temporal; PIT, Postero-infero-temporal; $S P$, Supero-parietal; IP, Infero-parietal; $O C$,

Occipital; CB, Cerebellum. Significant reductions in MS group were found on right supero-frontal lobe, both right and left infero-frontal lobe and left antero-supero-

temporal lobe. Pairs of comparisons were made using the Mann Whitney $U$ statistic. ${ }^{\star}=p<0.05$; $\star \star=p<0.01$. 
Table 3 Lobar $99 \mathrm{~m}$ Tc HMPAO asymmetry indices for MS patients and normal controls $(N C)^{\star}$

\begin{tabular}{llrl}
\hline Brain region & $N C(n=9)$ & $M S(n=17)$ & P value \\
\hline Supratentorial hemisphere & $0.8(0.8)$ & $2 \cdot 2(1.0)$ & NS \\
Frontal lobe & $0.5(1.8)$ & $-0.8(1.8)$ & NS \\
Temporal lobe & $0 \cdot 1(1.8)$ & $4 \cdot 7(1.9)$ & $<0.05$ \\
Parietal lobe & $0.6(0.9)$ & $2 \cdot 7(1.8)$ & $<0.01$ \\
Occipital lobe & $2.0(2.5)$ & $0.6(2.3)$ & NS \\
\hline
\end{tabular}

*Asymmetry indexes are presented as mean (SE). Positive asymmetry values correspond to relatively left sided hypoactivity, while negative values correspond to relatively left sided hyperactivity.

Pairs of comparison were made using the Mann Whitney U statistic.

total periventricular score, confluent lesion score and third ventricle index.

\section{SPECT evaluation}

In fig 1 are shown regional SPECT rates normalised to the mean cerebral activity rate $(Q$ values) for different brain regions in both $M S$ patients and healthy normal controls. Pairs of comparison for each region were made using the Mann Whitney U statistic.

The regions that showed a significant reduction in the MS group were right supero-frontal lobe, both right and left infero-frontal lobe, and left antero-supero-temporal lobe.

When the mean lobar asymmetry values were specifically examined (Mann Whitney U statistic), MS patients showed significant left side hypoactivity in the temporal and parietal lobes compared with controls (table 3 ).

\section{Relationship between neuropsychological and SPECT variables}

Intercorrelations were then examined between neuropsychological test scores and regional SPECT rates by using the Kendall tau test. Only variables which were significantly different from the control group were considered. Two out of 20 intercorrelations were significant. Left temporal side hypoactivity significantly correlated with the Set test $(p<0.01)$ and verbal memory measured by the Rey Auditory short term memory ( $<<0.01)$.

Figure 2 shows mean lobar $Q$ values for both MS subgroups as compared with normal controls $(n=9)$ by Dunnett's test. In the "cognitively intact" group ( $\mathrm{n}=9$ ), a significant depression was seen only in the right frontal lobe. On the other hand, the "cognitively

Figure 2 Mean (SE) lobar $Q$ values (lobar ROIs counts/whole brain counts) are shown for "cognitively impaired" $((n=8)$ and

"cognitively intact" $(n=9) M S$ patients compared with controls $(n=9)$. Significant reductions in mean $Q$ values as compared with controls are found in the right frontal lobes of both $M S$ groups and in left frontal and temporal lobes of "cognitively impaired" group. ${ }^{\star}=p<0.05$; $\star \star=p<0.01$; (Dunnett's test).

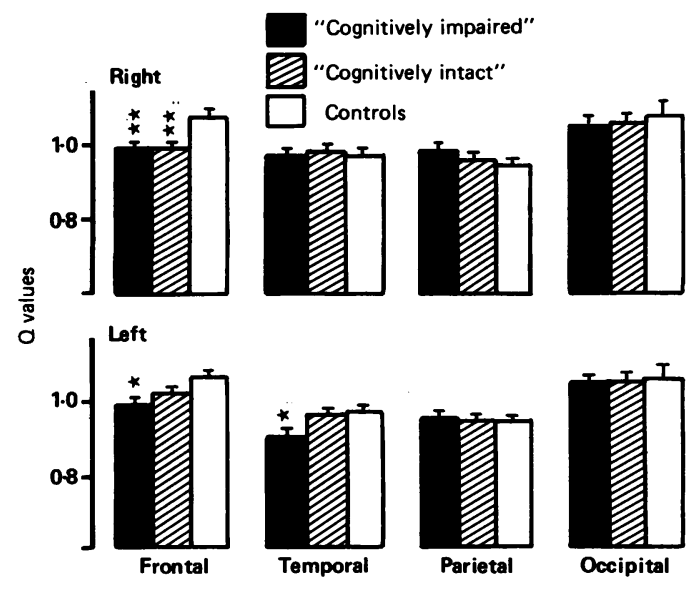

impaired" group ( $\mathrm{n}=8$ ) shows a significant decrease in the left temporal and bilateral frontal lobe.

\section{Discussion}

An impairment of cognitive functions including naming, verbal fluency, short and long term memory was detected in our MS sample although only relapsing-remitting patients and those with minimal physical disability (mean EDSS score of 1.7) were studied. These findings are consistent with the view that decline of cognition is not limited to the chronic-progressive patients or those with severe motor impairment. 2471011

The Rey Auditory Verbal Learning test in both the modalities (Short Term and Long Term) was the most sensitive test to elicit memory deficit, while Digit Span was not shown to be significantly impaired. Several studies have shown that short term memory capacity (that is, span memory) appears to be unaffected in $M S^{13-57}$ suggesting a specific memory problem in the learning ability rather than in retention. ${ }^{51031}$ Furthermore, in accordance with a number of previous studies, ${ }^{359}$ memory deficit was noted with both verbal and visuospatial material.

We found a significant impairment in the performances of verbal fluency and confrontational naming tests. While an impairment in verbal fluency has been widely described in MS, ${ }^{71031}$ there are only few reports suggesting naming difficulties in MS patients. ${ }^{132}$

Some authors found that major naming deficit is rare in relapsing remitting $M S$ patients being limited to patients with chronicprogressive disease. ${ }^{71}$ This discrepancy with our data may probably be due to variability among patient samples.

CT and more recently MRI have been used to determine whether a particular pattern of anatomic involvement correlated with cognitive and psychological disturbance in MS. ${ }^{12-18}$ Of several CT or MRI measures, the width of the third ventricle, ${ }^{12}$ periventricular lesion burden, ${ }^{15-17}$ total weighted lesion score ${ }^{1418}$ and corpus callosum atrophy ${ }^{1314}$ proved to be the most sensitive indicators of cognitive dysfunction.

In keeping with previous data we detected greater increase in the width of the third ventricle and higher "periventricular lesion score" in patients with mild cognitive disability compared with those with good overall performance. Moreover, a striking difference in "confluent lesion score" was noted between the two groups. This was not surprising, however, since confluent lesions were mainly periventricular. The two MS groups did not exhibit statistically significant differences in the callosal-brain ratio. Huber et $a^{13}$ found that callosal atrophy was only evident in patients with dementia and there was no distinction between patients with moderate and those with minimal intellectual impairment.

SPECT findings must be interpreted with caution. Tc99m HMPAO is a new radiopharmaceutical which passes the blood-brain 
barrier and is trapped inside functioning cells. ${ }^{33}$ Kinetic studies have shown that cerebral uptake of radioisotope is largely determined by regional blood flow, ${ }^{34}$ but at present quantitative data cannot be retrieved from SPECT studies. However, normalisation by the local/ global activity ratios may reduce within-group intersubject variability providing an index of regional brain perfusion.

The relationship between HMPAO uptake and cerebral perfusion is complicated in clinical situations, such as MS, by other factors including changes in tissue $\mathrm{PH}$, blood-brain barrier (BBB) alteration and presence of inflammatory cells able to take up the tracer. ${ }^{35}$

Pathological data have suggested that a common feature of active MS plaques is a local breakdown of the BBB associated with predominant lymphocitic infiltration. ${ }^{36}$ Although our patients have been examined during a stationary phase of the disease, the presence of recent active MS lesions could not be completely ruled out as recently documented using gadolinium enhanced MRI. ${ }^{378}$ It should, however, be emphasised that MS lesions are mainly confined to subcortical regions. Therefore, cortical hypoactivity observed in our patients is unlikely to be due to artefactual tracer uptake.

In this study, the regional 99mTc HMPAO uptake pattern indicates a predominant frontal abnormality and a greater left than right temporoparietal deficit in MS patients compared with normal subjects. In addition, lower activity in the left temporal lobe was found only in patients with cognitive impairment and correlated with a disorder in fluency and in verbal memory.

The pattern of a reduced activity affecting the frontal lobes observed in our patients is different from that associated with Alzheimer's disease where parieto-temporal cortex is compromised early and a frontal involvement is seen in the more advanced stages. ${ }^{39}$ Early frontal cortex hypometabolism was reported as a characteristic feature of "subcortical dementias" including progressive supranuclear palsy ${ }^{40}{ }^{41}$ and Huntington's disease. ${ }^{42}{ }^{43} \mathrm{MS}$ has not been commonly mentioned among the causes of subcortical dementia ${ }^{44}$ although the nature of cognitive impairment is compatible with the concept of subcortical dementia as recently suggested. ${ }^{5-45}$

Our data show a significant frontal SPECT abnormality despite certain neuropsychological tests measuring "frontal" functions (that is, Wisconsin Card sorting) which appeared to be relatively unaffected.

It has been suggested that patients with mild dementia caused by progressive supranuclear palsy may show metabolic reductions before neuropsychological changes occur. ${ }^{40}$ Furthermore, one may speculate that other neurological or behavioural patterns, which have not been tested in this study, could reveal an early frontal abnormality.

Recent evidence was found of prominent frontal release signs ${ }^{11}$ early attentional disturbance, ${ }^{18}$ and emotional symptoms ${ }^{16}$ in MS patients with mild physical disability.
The prevalent left supero-temporal hypoactivity seen in our MS patients was related to the poor performance on fluency and verbal memory tasks. Similar correlation between memory deficit and left temporal lobe has been recently reported using SPECT in Alzheimer's disease. $^{22}$

Reduced activity in the frontal and left temporal lobes may reflect cortical suppression or deactivation, secondary to disconnection from subcortical structures. Sporadic evidence of disconnection from well documented MS subcortical lesions has been recently reported. ${ }^{4647}$ Some authors have speculated that periventricular MS lesions may disrupt white matter fibre tracts interconnecting prefrontallimbic structures resulting in a deficit of memory and "frontal" functions.

The predominant left hemisphere dysfunction observed in this study seems not to be peculiar to MS since it has been recently demonstrated using SPECT and PET in Alzheimer's disease and multi-infarct dementia despite a lack of consistent asymmetrical pathological involvement in these diseases. ${ }^{20} 48$ On the other hand, symmetrical weighted lesions scores were also observed in our MS sample (see table 2). A series of hypotheses has been formulated to explain this lateralised brain dysfunction. The most likely explanation, however, was that the greater complexity of the left hemisphere organisation could lead to greater functional and behavioural deficit when both hemispheres are equally involved..$^{48}$

This study underlines the potential utility of SPECT in the investigation of cognitive dysfunction in MS. More specific information on the interrelationship between anatomic, neuropsychological and metabolic functions could be obtained using current PET scanning with higher resolution and sensitivity.

Research developed within the targeted project FATMA (prevention and control of risks factors), sub-project community medicine, of the CNR (Italian National Research Council), 1990-1995. The authors are indebted to Dr V Di Piero for helpful
suggestions, and to CMattei for technical assistance. We are also grateful to all the patients and their consultants for participating in this study.

1 Jambor KL. Cognitive functioning in multiple sclerosis. $\mathrm{Br}$ $J$ Psychiatry 1969;11:765-75.

2 Peyser JM, Edwards KR, Poser CM, et al. Cognitive function in patients with multiple sclerosis. Arch Neurol 1980;37:577-9.

3 Grant I, McDonald WI, Trimble MR, et al. Deficit learning and memory in early and middle phases of multiple
sclerosis. J Neurol Neurosurg Psychiatry 1984;47:250-5.

4 Rao SM, Hammeke TA, McQuillen MP, et al. Memory disturbance in chronic/progressive multiple sclerosis.
Arch Neurol 1984;41:625-31.

5 Rao SM. Neuropsychology of multiple sclerosis: a critical review. J Clin Exp Neuropsychol 1986;8:503-42.

6 Staples D, Lincoln NB. Intellectual impairment in multiple sclerosis and its relation to functional abilities. Rheumatol Rehab 1979;18:153-60.

7 Heaton RK, Nelson LM, Thompson DS, et al. Neuropsychological findings in relapsing/remitting and chronic/ progressive multiple sclerosis. J Consult Clin Psychol 1985;53:103-10.

8 Young AC, Saunders J, Ponsford JR. Mental change as an early feature of multiple sclerosis. $J$ Neurol Neurosurg Psychiatry 1976;39:1008-13.

9 Lyon-Caen $O$, Jouvent $R$, Hauser $S$, et al. Cognitive function in recent onset demyelinating disease. Arch Neurol 1986;43:1138-41.

10 Van den Burg W, Van Zomeren AH, Minderhoud JM, et al. Cognitive impairment in patients with multiple sclerosis and mild physical disability. Arch Neurol 1987;44: 494-501. 
11 Franklin GM, Nelson LM, Filley CM, et al. Cognitive loss in multiple sclerosis: Case reports and review of the literature. Arch Neurol 1989;46:162-7.

12 Rao SM, Glatt S, Hammeke TA, et al. Chronic progressive multiple sclerosis: Relationship between cerebral ventricular size and neuropsychological impairment. Arch Neurol 1985;42:678-82.

13 Huber SJ, Paulson GW, Shuttleworth EC, et al. Magnetic resonance imaging correlates of dementia in multiple sclerosis. Arch Neurol 1987;44:732-6.

14 Rao SM, Leo GJ, Haughton VM, et al. Correlation of magnetic resonance imaging with neuropsychological

15 Medaer R, Nelissen E, Appel B, et al. Magnetic resonance imaging and cognitive fu

16 Reischies FM, Baum K, Brau H, et al. Cerebral magnetic resonance imaging findings in multiple sclerosis: Relation resonance imaging findings in multiple sclerosis: Relation to disturbance of

17 Franklin GM, Heaton RK, Nelson LM, et al. Correlation of neuropsychological and MRI findings in chronic/progressive multiple sclerosis. Neurology 1988;38:1826-9.

18 Callananan MM, Logsdail SJ, Ron MA, et al. Cognitive impairment in patients with clinically isolated lesions of the type seen in multiple sclerosis: $A$ psychometric and MRI study. Brain 1989;112:361-74.

19 Brooks DJ, Leenders KL, Head G, et al. Studies on regional cerebral oxygen utilization and cognitive function in multiple sclerosis. J Neurol Neurosurg Psychiatry 1984;47: 1182-91.

20 Bonte FJ, Ross ED, Chehabi HH, et al. SPECT study of regional cerebral blood flow in Alzheimer's disease. regional cerebral blood flow in Al.

21 Perani D, Di Piero V, Vallar G, et al. Technetium-99m HMPAO-SPECT study of regional cerebral perfusion in early Alzheimer's disease. J Nucl Med 1988;29:1507-14.

22 Burns A, Philpot MP, Costa DC, et al. The investigation of Alzheimer's disease with single photon emission tomography. J Neurol Neurosurg Psychiatry 1989;52:248-53.

23 Schumacher GA, Beebe G, Kibler RF, et al. Problems of experimental trials in therapy in multiple sclerosis. Ann NY Acad Sci 1965;122:552-68.

24 Poser CM, Paty DW, Scheinberg L, et al. New diagnostic criteria for multiple sclerosis: guidelines for research protocols. Ann Neurol 1983;13:227-31.

25 Kurtzke JF. Rating neurologic impairment in multiple sclerosis: an expanded disability status scale (EDSS). Neurology 1983;33:1444-52.

26 Lezak MD. Neuropsychological assessment. New York: Oxford University Press, 1987.

27 Kaplan ED, Goodglass H, Weintraub S. Boston naming test. Philadelphia: Lea and Febiger, 1983.

28 Koopmans RA, Li P, Grochowski E, et al. Benign versus chronic progressive multiple sclerosis: Magnetic resonance features. Ann Neurol 1989;25:74-81.

29 Ormerod IEC, Miller DH, McDonald WI, et al. The role of NMR imaging in the assessment of multiple sclerosis and isolated neurological lesions: a quantitative study. Brain 1987;110:1579-616.

30 Reinars SJ, Coffman CE, Smoker WRK, et al. MR imaging of the corpus callosum: Normal and pathologic findings and correlation with CT. $A J N R$ 1988;9:649-56.
31 Beatty WW, Goodkin DE, Monson $\mathrm{N}$, et al. Cognitive disturbances in patients with relapsing remitting multiple sclerosis. Arch Neurol 1989;46:1113-9.

32 Caine ED, Bamford KA, Schiffer RB, et al. A controlled neuropsychological comparison of Huntington's disease and multiple sclerosis. Arch Neurol 1986;43:249-54.

33 Leonard JP, Nowotnik DP, Neirincks RD, et al. Technetium-99m-d, 1-HM-PAO: a new radiopharmaceutical for imaging regional brain perfusion using SPECT. A comparison with iodine-123 HIPDM. J Nucl Med 1986 27:1819-23.

34 Lucignani G, Perani D, Rossetti C, et al. Biodistribution and clinical evaluation of $99 \mathrm{~m}$ Tc HM-PAO: A tracer for CBF assessment by SPECT'. J Cereb Blood Flow Metab 1987;7: S538.

35 Peters AM, Dampure HJ, Osman S, et al. Clinical experience with $99 \mathrm{~m}$ Tc hexamethylpropyleneamineoxime for labelling leucocytes and imaging inflammation. oxime for labelling leuco

36 Broman T. Blood-brain barrier damage in multiple sclerosis: supravital test-observations. Acta Neurol Scand 1964;40 supravital test-o

37 Miller DH, Rudge P, Johnson G, et al. Serial gadolinium enhanced magnetic resonance imaging in multiple sclerosis. Brain 1988;111:927-39.

38 Bastianello S, Pozzilli C, Bernardi S, et al. Serial study of Gadolinium-DTPA MRI enhancement in multiple sclerosis. Neurology 1990;40:591-5.

39 Frackowiak RSJ, Pozzilli C, Legg NJ, et al. Regional cerebral oxygen supply and utilization in dementia: A clinical and physiological study with oxygen-15 and positron tomography. Brain 1981;104:753-78.

40 D'Antona R, Baron JC, Samson Y, et al. Subcortical dementia: Frontal cortex hypometabolism detected by positron tomography in patients with progressive suprapositron tomography in patients with
nuclear palsy. Brain 1985;108:785-99.

41 Goffinet AM, De Volder AG, Gillain C, et al. Positron tomography demonstrates frontal lobe hypometabolism in progressive supranuclear palsy. Ann Neurol 1989;25: $131-9$.

42 Pantano P, Lenzi GL, Berardelli A, et al. Regional CBF pattern in patients with Huntington's disease. $J$ Cereb Blood Flow Metab 1989;9:S22.

43 Hasselbach S, Andersen A, Sorensen S, et al. Regional cerebral blood flow in Huntington's disease using SPECT and 99m Tc-HMPAO. J Cereb Blood Flow Metab 1989;9: S350.

44 Cummings JL, Benson DF. Subcortical dementia: review of an emerging concept. Arch Neurol 1984;41:874-9.

45 Filley CF, Heaton RK, Nelson LM, et al. A comparison of dementia in Alzheimer's disease and multiple sclerosis. Arch Neurol 1989;46:157-61.

46 Herscovitch P, Trotter JL, Lemann W, et al. Positron emission tomography (PET) in active MS: Demonstration emission tomography (PET) in active MS: Demonstration of demyelinat

47 Pozzilli C, Pantano P, Bozzao L, et al. Sequential computed tomography and 123 I-HIPDM scans in multiple sclerosis with large plaque: A case report. Eur Neurol 1987;27 88-91.

48 Loewenstein DA, Barker WW, Chang JY, et al. Predominant left hemisphere metabolic dysfunction in dementia. Arch Neurol 1989;46:146-52. 